\title{
PUBLICATIONS RECEIVED BEFORE 1981, AUG. 31ST
}

Bilý, Milan, Intrasentential Pronominalization and Functional Sentence Perspective (in Czech, Russian and English) (= Lund Slavonic Monographs 1), Slaviska Institutionen vid Lunds universitet, Lund 1981, 232 pp.

Chvatik, Květoslav, Tschechoslowakischer Strukturalismus (=Theorie und Geschichte der Literatur und der schönen Künste 61), Wilhelm Fink Verlag, München 1981, 283 pp.

Steensland, Lars, A Method for Measuring Perceptual Distances between Different Vowel Qualities. Some Identification Tests Using Russian /e/Variants and Swedish Subjects (=Acta Universitatis Upsaliensis, Studia Slavica Uppsaliensia 21), Uppsala 1981, 93 pp.

Steensland, Lars, Formantstrukturen hos ryska e-allofoner (=Uppsala Slavic Papers 3), Uppsala University, Department of Slavic Languages, Uppsala 1981, 60 pp.

Живов, В. М., Очерки по синтагматической фонологии, Издательство Московского университета, Москва 1980, 238 стр.

Gusli Nr. 1, Contemporary Problems in Linguistic Terminology, Göteborg 1980, Slaviska Institutionen vid Göteborgs universitet, $89 \mathrm{pp}$.

Slavica Lundensia 8, Bohemica et Slovaca, Lund 1980, Slaviska Institutionen vid Lunds universitet, $137 \mathrm{pp}$.

Russian Linguistics 6 (1982) 305. 0304-3487/82/0062-0305\$00.10.

Copyright (C) 1982 by D. Reidel Publishing Co., Dordrecht, Holland, and Boston, U.S.A. 